\title{
A Multi-Parameter Evaluation of the Neuroprotective and Cognitive-Enhancing Effects of Origanum Onites L. (Turkish Oregano) Essential Oil on Scopolamine-Induced Amnestic Rats
}

\section{Asli Aykac ( $\square$ aykacasli@yahoo.com )}

Near East University: Yakin Dogu Universitesi https://orcid.org/0000-0002-4885-5070

Kerem Teralı

Girne American University - Karmi Campus: Girne Amerikan Universitesi

Dilek Özbeyli

Marmara Üniversitesi: Marmara Universitesi

\section{Seren Ede}

Marmara Üniversitesi: Marmara Universitesi

\section{Ömercan Albayrak}

Marmara Universitesi - Goztepe Kampusu: Marmara Universitesi

\section{Kemal Hüsnü Can Başer}

Near East University: Yakin Dogu Universitesi

\section{Göksel Şener}

Fenerbahçe Üniversitesi: Fenerbahce Universitesi

\section{Research Article}

Keywords: scopolamine-induced amnesia, Alzheimer's disease, oxidative stress, neuroinflammation, apoptosis, Origanum onites.

Posted Date: December 20th, 2021

DOI: https://doi.org/10.21203/rs.3.rs-1148541/v1

License: (9) This work is licensed under a Creative Commons Attribution 4.0 International License. Read Full License

Version of Record: A version of this preprint was published at Metabolic Brain Disease on February 24th, 2022. See the published version at https://doi.org/10.1007/s11011-022-00933-6. 


\section{Abstract}

Alzheimer's disease (AD) is a neurodegenerative disorder characterized by progressive deterioration of cognitive functions (dementia) and represents a growing public health concern since the population in the age groups at risk is increasing. The latter raises an urgent need to translate research findings in the basic brain and behavioral sciences into anti-AD drugs and disease-modifying therapies. Origanum onites (L.), also called Turkish oregano, is a perennial and herbaceous plant species grown for centuries for medicinal, cosmetic and culinary purposes. This is the first study to investigate the putative neuroprotective and pro-cognitive activities of $O$. onites essential oil (OOEO) against scopolamineinduced amnesia of AD-type in Wistar albino rats. The results of behavioral tests revealed that OOEO administration was able to significantly alleviate learning and memory impairments induced by scopolamine in vivo. The observed effects could be attributed to inhibition of acetylcholinesterase activity, attenuation of oxidative stress and prevention of neuronal apoptosis in the hippocampus and frontal cortex of $A D$ rats. Modulation of pro-inflammatory enzymes, including cyclooxygenase-2, inducible nitric oxide synthase and myeloperoxidase, might further contribute to the neuroprotective properties of OEOO, as predicted by our in silico models. These findings offer novel insights into the therapeutic potential of OEOO in patients with AD.

\section{Introduction}

Alzheimer's disease (AD) is an aging-related neurodegenerative disorder with progression, which is manifest in both cognitive and neuropsychiatric symptoms (Soria Lopez et al. 2019). The progression of the $A D$ continuum causes deficits in cognitive functions to become more perceptible. It is commonly believed that a loss of cholinergic neurons from the forebrain and a corresponding decrease in acetylcholine levels, both of which represent hallmarks of AD pathology, predispose to dementia (FerreiraVieira et al. 2016). Changes in cholinergic transmission, oxidative stress, inflammation or monoaminergic disorders can be counted among the different causes of memory loss in dementia. With these effects, neuronal apoptosis and consequent memory disorders develop (Deng et al. 2019).

Today, the administration of acetylcholinesterase (AChE) inhibitors appears to provide the most promising results in the symptomatic treatment of mild to moderately severe AD. While the patient's learning and memory functions are improved by increasing the acetylcholine levels by means of AChE inhibitors, they also possess limitations due to the side effects caused by the activation of the cholinergic system (Deng et al., 2019). Furthermore, there is compelling evidence showing that chronic inflammation (neuroinflammation) significantly contributes to the pathogenesis of AD (Kinney et al. 2018). A number of pro-inflammatory mediators, including inducible enzyme systems, are known to be associated with this sustained immune response in the brain. Therefore, it is no surprise that anti-inflammatory interventions may show efficacy in treating AD. However, efforts to prevent dementia by using aspirin and other nonsteroidal anti-inflammatory drugs (NSAIDs) have generally been unsuccessful to date (Jordan et al. 2020). 
The science of natural medicine, which has been around for centuries, greatly supports the need for both different drug applications and clinical drugs. Precious compounds in natural products serve to form the basis of modern drug research as well as to guide research which leads to the best possible cure (Howes et al. 2003). Due to the limitations of current therapy, treatment regimens that can benefit from AD modifying and/or preventive agents in daily tasks that require cognitive functions have come into focus (Farlow et al. 2008). In this context, medicinal plants known or researched to have anti-inflammatory, antioxidant, neuroprotective effects have become the focus (Perry et al. 2003; Rabiei et al. 2015; Xu et al. 2017; Capatina et al. 2020).

Scopolamine ( $\mathrm{Sco}$ ) is an alkaloid drug that produces antagonism at muscarinic acetylcholine receptors (mAChRs) by interfering with cholinergic transmission, impairing learning and short-term memory in both rodents and humans (Zhou et al. 2018). Therefore, Sco has been used in many preclinical studies to screen drugs with potential therapeutic values in dementia patients with $A D$ to produce an amnesia model (Rezvani et al. 2011; Zhou et al. 2018). The literature provides important evidence stating that Sco has numerous effects in the brain, such as oxidative stress, which eventually cause cognitive impairment (Rahnama et al. 2015). It has been reported that natural products or plant components, some of which are currently in use as potent AChE inhibitors, can reverse memory deficits in studies using various animal models, including Sco-induced models (Savelev et al. 2004; Rabiei et al. 2015).

Origanum onites L. (also known as Turkish oregano) is used as a raw drug for the treatment of respiratory tract diseases, hypertension, and high cholesterol, as well as an analgesic, sedative, and general oral antiseptic (Tepe et al. 2016). Thymol and carvacrol, which are the two major components in the essential oils of many aromatic plants as in Origanum onites essential oil (OOEO), have antioxidant, anti-inflammatory and AChE-inhibitory properties that could be effective in treating the cognitive symptoms of AD (Baser et al. 2008; Azizi et al. 2012). The current study, which is the first of its kind, aims at evaluating the influence of OOEO on the acquisition and consolidation of memory and learning processes impaired by Sco treatment in Wistar albino rats using behavioral tests. It also attempts to investigate the underlying pathophysiological mechanisms of cognitive dysfunction through assaying the activity of AChE and determining the levels of the oxidative stress markers malondialdehyde (MDA) and reduced glutathione (GSH) as well as of the mitochondria-mediated apoptosis markers bcl-2, bax, caspase (casp)-3 and casp-9 in the frontal cortex and hippocampus of the animals. Finally, in order to estimate the anti-inflammatory activity of OOEO, the major component of the essential oil is docked in a computational setting onto three selected pro-inflammatory enzymes, namely cyclooxygenase-2 (COX-2), inducible nitric oxide synthase (iNOS), and myeloperoxidase (MPO).

\section{Materials And Methods}

\subsection{OOEO and chemicals}

OOEO was procured from TÜRER, Inc. (Izmir, Turkey). The identity of the source plant was confirmed by comparison with a sample stored in the Başer Library of Essential Oil Constituents (ESSE 14567, 
Eskisehir, Turkey). Unless stated otherwise, all chemicals and all antibodies were purchased from SigmaAldrich Co. (St. Louis, Missouri, USA) and Santa Cruz Biotechnology, Inc. (Santa Cruz, CA, USA), respectively.

\subsection{Analysis of OOEO and identification of its components}

OOEO was analyzed by gas chromatography/mass spectrometry (GC/MS) using the Agilent 5977B GC/MSD system, and the relative percentages of successfully separated compounds were computed from the corresponding flame ionization detector peak areas according to previously described methods (Demirci et al. 2004; Aykac et al. 2020). Retention indices were determined using n-alkane standards as reference, while retention indices were compared with those of authentic samples.

\subsection{Animals}

Female rats (Wistar albino), weighing 200-250 g, were obtained from Marmara University Experimental Animals Research and Implementation Center (İstanbul, Turkey). All experiments were approved by Research and Local Committee on Animal Research Ethics of Marmara University (approval no. 81.2019.mar) and executed in accordance with the "Guide for the Care and Use at Laboratory Animals. All rats were housed in cages ( $\mathrm{n}=3$ rats per cage) in a controlled 12-h light/dark cycle at a humidity of $50 \pm$ $5 \%$ and a temperature of $22 \pm 2^{\circ} \mathrm{C}$. Rats were allowed to access water and food ad libitum. The rats housed in the above-mentioned habituation conditions one week before the behavioral experiments started were randomly divided into five groups ( $n=6$ rats in each group).

\subsection{Modeling amnesia and construction of experimental groups}

Groups of rats received i.p. injections of scopolamine (Sco, $1 \mathrm{mg} / \mathrm{kg}$ ) (Ghasemi et al. 2018; Aykaç et al. 2019) and OOEO (0.25 ml/kg, p.o.) (Amiresmaeili et al. 2018) or an equal amount $(0.25 \mathrm{ml} / \mathrm{kg})$ of the vehicle $(0.1 \% \mathrm{v} / \mathrm{v}$ Tween 80$) 30$ min before Morris water maze (MWM) test section each day. The control group received saline ( $0.9 \% \mathrm{w} / \mathrm{v} \mathrm{NaCl}$, i.p.), or galantamine (Gal, $1.5 \mathrm{mg} / \mathrm{kg}$, i.p.) (Geerts et al. 2005 ) or OOEO $(0.25 \mathrm{ml} / \mathrm{kg}$, p.o.) instead of Sco. All treatments were given at 9 a.m. for 14 consecutive days (Fig. 1). Locomotor activity, MWM and novel object recognition (NOR) tests were performed to evaluate cognition, learning, recognition and spatial memory function in rats.

\subsection{Locomotor activity test}

For each rat, the number of total transitions between the squares and rearing frequencies were recorded for 5 min with the help of a video camera hanging above the apparatus consisting of a total of 25 squares, with the side length of each square being $15 \mathrm{~cm}$ (Rogóż et al. 2012).

\subsection{NOR test}

The NOR test was carried out for each rat in three stages as follows: habituation, familiarization, and test. The rat was placed in a box $(65 \mathrm{~cm} \times 45 \mathrm{~cm} \times 65 \mathrm{~cm})$ for $10 \mathrm{~min}$ in the habituation phase. The next day, 
the behavior of the rat placed in the box with two identical objects of the same shape and color was recorded for $10 \mathrm{~min}$ in the familiarization phase. After the familiarization phase, the rat was allowed to stay in its cage for $1 \mathrm{~h}$. The behavior of the rat in the box containing one of the sample objects used in the familiarization phase (old object) and a novel (new) object is observed for 3 min and record using a video camera (Antunes and Biala 2012). After each animal completed the NOR test, all used boxes and objects were cleaned with a solution containing $70 \%(\mathrm{v} / \mathrm{v})$ ethanol and the next rat's behavior experiments were started. The results obtained from the NOR test are expressed as the index of discrimination with results ranging from -1 to +1 (Aubele et al. 2008).

Discrimination index $(s)=$ (Time spent with the novel object - Time spent with the sample object) / (Time spent with the novel object + Time spent with the sample object).

\subsection{MWM test}

The maze was an open circular pool (diameter of $1.2 \mathrm{~m}$, a height of $0.47 \mathrm{~m}$ and depth of $30 \mathrm{~cm}$ ) approximately half-filled with water made opacified with milk powder (water temperature is $24-26^{\circ} \mathrm{C}$ ). MWM task consists of the training period and probe trials. While there was a platform in the MWM tests from day 1 to day 4 (training period), there was no platform in the tank in day 5 experiments (probe trial). The pool was divided into four equal quadrants (quarter-circles) and a platform was hidden $2 \mathrm{~cm}$ below the surface in the northeast (NE) direction on the first day of the experiments (Vorhees and Williams 2006). In the first 4 day, each rat received three training sessions per day. In these 4-day training experiments, rats were randomly released from one of the four quadrants (NE, SE, SW, or NW direction) into the maze and allowed to swim for $75 \mathrm{~s}$ to find the platform. Platform finding times of rats in $60 \mathrm{~s}$ are recorded. The animals that failed to find the platform within this period are directed to the platform allowed to stay there for $20 \mathrm{~s}$ and their platform finding times are saved as $60 \mathrm{~s}$. The swimming activity of each rat, which will be used to evaluate the escape delay and escape rate, was recorded using a fixed video camera hung from the ceiling. On the day of the probe test, in the NE direction, the platform was lifted and the rat was allowed to swim for $60 \mathrm{~s}$ by releasing it into the tank from SW (the opposite direction of NE). The time spent in the target quadrant was recorded for each rat.

\subsection{Euthanasia and removal of brain tissue samples}

The rats were deep anesthetized with thiopental sodium at $50 \mathrm{mg} / \mathrm{kg}$ (Actavis; Archimedes Pharma, Reading, UK) immediately after the last cognitive test session, and their brains were dissected into different anatomical regions. The hippocampus (anteroposterior plane: between $6.70-4.70 \mathrm{~mm}$ anterior to the inter-aural line) and frontal cortex (anteroposterior plane: between 13.20-11.20 mm anterior to the inter-aural line) were sliced according to the coordinates stated in Paxinos and Watson's Rat Brain Atlas (2007).

\subsection{Determination of AChE activity and measurement of MDA and GSH levels in different brain tissues}


The activity of AChE, which is responsible for the degradation of acetylcholine in tissue samples, was determined using an acetylcholinesterase colorimetric commercial kit by Abcam (ab138871) and was expressed in $\mathrm{U} / \mathrm{mg}$ protein. The assay was performed according to the manufacturer's instructions, and the activity was measured at $410 \mathrm{~nm}$ using a spectrophotometer. In cortex and hippocampal tissue samples, MDA levels (expressed as nmol/mg protein) were measured using a commercial test kit (ab118970, Abcam), while GSH levels (expressed as $\mu \mathrm{g} / \mathrm{mg}$ protein) were measured according to the method described previously (Wang et al. 2019). All readings were made on a universal microplate spectrophotometer (MDA at $532 \mathrm{~nm}, \mathrm{GSH}$ at $420 \mathrm{~nm}$ ).

\subsection{Immunoblotting analysis}

The immunoblotting analysis, which is used to determine the total amount of protein present in the tissues, was briefly performed as follows: the protein content of the prefixes was determined by the Lowry method (Lowry et al. 1951) after centrifuging the tissues in Tris-HCl (pH 7.2) buffer. Samples containing $100 \mu \mathrm{g}$ protein were loaded onto a $12 \%$ sodium dodecyl sulfate-polyacrylamide gel (SDS-PAGE) and then transferred onto the membranes (Schleicher and Schuell, $0.45 \mu \mathrm{m}$, Germany). All membranes were incubated with polyclonal primary antibodies for $12 \mathrm{~h}$. All antibodies were used at a dilution of 1:100, except bax (1:200). The $\beta$-actin expression levels were used as a standard for all membranes. Protein bands were visualized by NBT/BCIP on membranes incubated with secondary antibody for 1 hour. Densitometric analysis of all membranes was performed using Bio-Rad Molecular Analyst software (www.totallab.com). Molecular weights for $\beta$-actin, bax, bcl-2, casp-3 and casp-9 are 43, 23, 26, 20 and 35 $\mathrm{kDa}$ respectively.

\subsection{Protein-ligand docking}

The 3D conformer of carvacrol (PubChem entry: 10364) in SDF format was retrieved from the public chemical database PubChem (Kim et al. 2019) and separately docked onto the crystal structures of three selected human pro-inflammatory enzymes - namely, COX-2 (PDB entry: 5KIR) (Orlando and Malkowski, 2016), inducible iNOS; (PDB entry: 3E7G) (Garcin et al. 2008) and MPO (PDB entry: 5QJ2) (Wurtz et al. 2018) - using the fully automated protein-ligand docking tool JAMDA (Schellhammer and Rarey 2007; Henzler et al. 2014; Flachsenberg et al. 2020) available at https://proteins.plus (Fährrolfes et al. 2017; Schöning-Stierand et al. 2020). Each protein was prepared through the Protoss optimization routine, in which cofactors and structurally relevant water molecules were maintained. Each binding site was defined by the corresponding bona fide inhibitor, with a site radius of $6.5 \AA$. Molecular docking was executed with high precision.

\subsection{Statistical analysis}

All data were analyzed using the GraphPad Prism 6 tool (GraphPad Software Inc., San Diego, CA, USA) and expressed as means \pm SEM. Indexes in acquisition of MWM trials, such as escape latency and escape rate, were analyzed by repeated-measure two-way ANOVA. One-way ANOVA followed by a 
Bonferroni post hoc test was used in the analysis of the other behavior parameters, biochemical and molecular experiments. For all statistical analyses, $p<0.05$ was considered statistically significant.

\section{Results}

\subsection{Characterization of OOEO}

In the chemical analysis of OOEO, 32 individual components were determined, four of which constituted $90.8 \%$ of the said essential oil (Aykac et al. 2020; Table 1). The two major components of OOEO were found to be carvacrol and $\mathrm{\gamma}$-terpinene $(78.7 \%$ and $6.9 \%$, respectively). 
Table 1

Compositional analysis of Origanum onites essential oil

\begin{tabular}{|c|c|c|c|}
\hline LRI & RRI & Compound name & $\begin{array}{l}\text { Relative percentage amounts }(\%) \text { in the essential oil of } \\
\text { Origanum onites }\end{array}$ \\
\hline 1020 & 1032 & a-Pinene & 0.4 \\
\hline 1024 & 1035 & a-Thujene & 1.1 \\
\hline 1072 & 1076 & Camphene & 0.3 \\
\hline 1119 & 1118 & $\beta$-Terpinene & 0.1 \\
\hline 1172 & 1174 & Myrcene & 0.6 \\
\hline 1177 & 1179 & a-Phellandrene & 0.2 \\
\hline 1191 & 1188 & a-Terpinene & 1.3 \\
\hline 1213 & 1203 & Limonene & 0.2 \\
\hline 1222 & 1218 & $\beta$-Phellandrene & 0.2 \\
\hline 1260 & 1255 & $\mathrm{Y}$-Terpinene & 6.9 \\
\hline 1287 & 1280 & $p$-Cymene & 4.1 \\
\hline 1298 & 1290 & Terpinolene & 0.1 \\
\hline 1457 & 1452 & 1-Octen-3-ol & 0.1 \\
\hline 1478 & 1474 & $\begin{array}{l}\text { trans-Sabinene } \\
\text { hydrate }\end{array}$ & 0.4 \\
\hline 1555 & 1553 & Linalool & 1.4 \\
\hline 1564 & 1556 & $\begin{array}{l}\text { cis-Sabinene } \\
\text { hydrate }\end{array}$ & 0.2 \\
\hline 1569 & 1565 & Linalyl acetate & 0.1 \\
\hline 1624 & 1609 & Terpinene-4-ol & 0.7 \\
\hline 1628 & 1612 & $\beta$-Caryophyllene & 0.5 \\
\hline 1638 & 1628 & Aromadendrene & 0.1 \\
\hline 1717 & 1706 & a-Terpineol & 0.2 \\
\hline 1728 & 1719 & Borneol & 0.4 \\
\hline 1748 & 1741 & $\beta$-Bisabolene & 1.1 \\
\hline 1770 & 1751 & Carvone & $\operatorname{Tr}$ \\
\hline
\end{tabular}




\begin{tabular}{|llll|}
\hline LRI & RRI & Compound name & $\begin{array}{l}\text { Relative percentage amounts (\%) in the essential oil of } \\
\text { Origanum onites }\end{array}$ \\
\hline 1786 & 1773 & $\delta$-Cadinene & $\operatorname{Tr}$ \\
\hline 1793 & 1776 & Y-Cadinene & 0.1 \\
\hline 1899 & 1890 & Carvacryl acetate & 0.1 \\
\hline 2033 & 2008 & $\begin{array}{l}\text { Caryophyllene } \\
\text { oxide }\end{array}$ & 0.1 \\
\hline 2159 & 2144 & Spathunelol & 0.1 \\
\hline 2205 & 2187 & T-Cadinol & 0.2 \\
\hline 2210 & 2198 & Thymol & 0.2 \\
\hline 2243 & 2239 & Carvacrol & 78.4 \\
\hline & Total & 100.0 \\
\hline
\end{tabular}

\subsection{Effect of OOEO on locomotor activity in Sco-induced amnestic rats}

The locomotor activity test was used to evaluate the negative effects on cognitive behavior such as spontaneous exploratory activities and arousal that may be caused by the administrated treatments. Our results suggest that Gal, OOEO, Sco and ScO+OOEO treatments did not affect the overall locomotor activities of rats $[F(4,32)=0.491$ and $F(4,32)=0.714$, respectively; $p>0.05]$. It was determined that Scoinduced amnesia group had less rearing frequency and shorter total distance travelled in 5 min compared to the ScO+OOEO groups, however, there was no significant change in the total distance between all groups (Fig. 2a, b).

\subsection{OOEO ameliorated cognitive function and spatial memory in amnestic rats induced by Sco}

Significant differences were identified between the treatment groups with the NOR test, which was designed to assess short-term recognition memory $(F=8.649, p<0.001)$. The discrimination index was significantly reduced in Sco-induced amnesia rats compared to control rats $(p<0.05)$ and showed defective cognitive abilities (Fig. 2c). The administration of OOEO treatment to the amnestic rats (ScO+OOEO group) increased the discrimination index compared to the Sco group $(p<0.001)$. The discrimination index was significantly increased in Gal and OOEO groups compared to the Sco-induced amnesia group ( $p<0.05$, in both groups). 
It was determined that there were significant differences in escape latency between training days $(\mathrm{F}=$ $567.6, p<0.001)$ and treatment groups $(F=177.8, p<0.001)$. It was observed that the rats in the amnesia group had longer escape latency than the control group from the second training day $(p<0.001)$ and showed little improvement during training days (Fig. 3a). Administration of OOEO treatment to the Scoinduced amnesia group significantly shortened this latency prolongation on the second to fifth day $(p<$ 0.001). It was determined that the escape latency of Gal and OOEO treatment groups was shortened from the second day when compared with the Sco-induced amnesia group ( $p<0.001$ for both group).

Analysis of the escape rate displayed significant differences in treatment groups $(F=446.8, p<0.001)$ and training days $(F=137.8, p<0.001)$ (Fig. $3 b)$. The rats in the Sco-induced amnesia group maintained statistically significant lower escape rate than control rats from the second day ( $p<0.001 ;$ Fig. $3 b)$. It was determined that the escape rate of the Sco+OOEO group increased significantly on the second day $(p<$ 0.001). The escape rate of $\mathrm{Gal}$ and OOEO treatment groups was increased from the second day when compared with the Sco-induced amnesia group $(p<0.001$ for both groups).

Significant differences were determined between the time spent in the target quadrant between treatment groups in the probe experiments without a platform on the fifth day $(F=8.473, p<0.001$; Fig. $3 c)$. In the research trial to determine if they remembered platform localization, the time spent in the target quarter was significantly reduced in the Sco-induced amnesia group compared to the control group $(p<0.001)$. OOEO treatment applied to the amnesia group significantly increased the time spent in the target quadrant compared to the Sco-induced amnesia group $(p<0.001)$. It was determined that the time spent in the target quadrant increased significantly in the Gal and OOEO groups compared to the Sco-induced amnesia group $(p<0.001)$.

\subsection{OOEO reversed the progressive loss of cholinergic function and oxidative stress parameters in} amnestic rats induced by Sco

The MDA levels of frontal cortex and hippocampus regions, an indicator of lipid peroxidation, was increased in the Sco-induced amnesia group as compared to the control group $(p<0.001)$ (Fig. $4 \mathrm{a}, \mathrm{b})$. In Gal, OOEO and Sco+OOEO groups, MDA level significantly decreased in both regions comparing to Scoinduced amnesia group $(p<0.001)$. The GSH levels of both regions was decreased in the Sco-induced amnesia group as compared to the control group $(p<0.001)$. In Gal, OOEO and Sco+OOEO groups, GSH level significantly increased in cortex comparing to Sco-induced group $(p<0.001, p<0.001$ and $p<0.01$, respectively) (Fig. 4c), as in the hippocampus region ( $p<0.01, p<0.01$, and $p<0.05$, respectively) (Fig. 4d). AChE activity was increased in both regions in the Sco-induced group compared to the control group ( $p<0.001$, Fig. $4 \mathrm{e}$ and $p<0.01$, Fig. 4 f). Gal and OOEO treatment significantly reduced AChE activity compared to the Sco-induced group in cortex ( $p<0.001$ in both groups), as in the hippocampus ( $p$ $<0.05$ in both groups). Thus, OOEO expressed an anti-AChE feature, which parallels improving memory function in rats, as observed in behavior tests. 


\subsection{OOEO reduced apoptosis in the two different brain regions of Sco-induced amnestic rats}

Intrinsic apoptosis, a type of mitochondria-centered cell death, is characterized by the formation of apoptosomes, activation of casp-9 and subsequent activation of effector caspases. Essentially, the entire process is regulated by the BCL-2 family of proteins and maintained by the caspase family of proteins (Tang, 2019).

The ratio of bax to bcl-2 in the frontal cortex and hippocampal regions, an indicator of apoptosis, was increased in the Sco-induced amnesia group as compared to the control group $(p<0.001$ and $p<0.01)$ (Fig. $5 \mathrm{a}, \mathrm{b}$ ). In Gal, OOEO and Sco+OOEO groups, the bax/bcl-2 ratio was significantly decreased in cortex $(p<0.001, p<0.01$ and $p<0.05)$ and hippocampus regions $(p<0.001, p<0.05$ and $p<0.05$, respectively) comparing to Sco-induced group.

The expression levels of casp-3 and -9 in the frontal cortex and hippocampus, an indicator of intrinsic apoptosis, were increased in the Sco-induced amnesia group as compared to the control group $(p<0.001$ for frontal cortex in both expression level; for hippocampus $p<0.001$ and $p<0.01$, respectively) (Fig. 5d, f). In Gal, OOEO and Sco+OOEO groups, casp-3 levels significantly decreased in frontal cortex $(p<0.001$, $p<0.001$ and $p<0.05$, respectively) and hippocampus regions $(p<0.01, p<0.001$ and $p<0.05$, respectively) comparing to Sco-induced group. In Gal, OOEO and Sco+OOEO groups, casp-9 levels significantly decreased in frontal cortex ( $p<0.01$ in all groups) and hippocampus regions $(p<0.001, p<$ 0.001 and $p<0.05$, respectively) comparing to Sco-induced group.

\subsection{Carvacrol could be accommodated within the inhibitor- binding pockets of selected pro-inflammatory enzymes}

In an attempt to speculate about the possible anti-inflammatory effects of OOEO in the human body, we docked its major bioactive component carvacrol onto three of the known enzymes of inflammation -namely, COX-2, iNOS and MPO. The results of redocking calculations demonstrated that JAMDA was able to reproduce the crystallographic binding modes of the bona fide enzyme inhibitors well, with rootmean-square deviations (RMSDs) less than $1 \AA$ (Table 2). In cross-docking experiments, carvacrol was found to be able to occupy the inhibitor-binding sites of COX-2, iNOS and MPO, albeit with lower docking scores compared to those for the bona fide inhibitors. The binding of carvacrol at the said sites of COX-2, iNOS and MPO appeared to be stabilized mainly by van der Waals forces and hydrophobic interactions (Fig. 6). In the case of the predicted MPO-carvacrol complex, $\pi-\sigma$ (at $3.48 \AA$ ) and $\pi$-alkyl (at $4.07 \AA$ ) interactions were found to occur between the ligand and the heme prosthetic group of the protein. 
Table 2

Derived docking scores relating to the best-selected

binding pose for carvacrol in the inhibitor-binding

pockets of pro-inflammatory enzymes.

\begin{tabular}{|llll|}
\hline & \multicolumn{2}{l}{ Bona fide inhibitor } & Carvacrol \\
\cline { 2 - 4 } & Docking score & RMSD & Docking score \\
\hline COX-2 $^{*}$ & -2.52030 & $0.532 \AA$ & -1.65951 \\
\hline iNOS $^{\dagger}$ & -2.62362 & $0.682 \AA$ & -1.66283 \\
\hline MPO $^{\ddagger}$ & -2.32663 & $0.632 \AA$ & -1.64903 \\
\hline
\end{tabular}

*: PDB entry 5KIR

t: PDB entry 3E7G

‡. PDB entry 5QJ2

\section{Discussion}

With a rapidly growing elderly population worldwide, a focus on finding efficient preventive and therapeutic strategies in the management of $A D$ should prove timely and topical to researchers. The available evidence suggests that culinary herbs, such as Melissa officinalis L. (Lamiaceae), can potentially provide a natural treatment for AD (Howes et al. 2003; Gürbüz et al. 2019). In the relevant scientific literature, there also exist other studies indicating various clinical, cholinesterase inhibitory and neurobiological activities of different Lamiaceae plants (Perry et al. 2003; Orhan et al. 2008). All these as well as previous promising yet limited work on the bioactivity of traditionally consumed 0 . onites $\mathrm{L}$. have enabled us in designing and executing the current study, in which the previously underdetermined neurobiological activity of the essential oil from this herb was investigated thoroughly. Putative neuroprotective and cognitive-ameliorating effects of OOEO on Sco-induced learning and memory impairments in rats were examined by behavioral tests, biochemical assessment, and computational simulations.

Here, we evaluated the cognitive effects of OOEO on memory and learning as well as the possible mechanisms underlying these effects in a rat model of Sco-induced amnesia. Initially, we tested whether OOEO treatment caused changes in behavioral parameters, such as locomotory activity and learning and memory abilities, in rats. Our results suggest that OOEO administered at a dose of $0.25 \mathrm{ml} / \mathrm{kg}$ enhanced memory functions previously impaired by Sco, corrected the negative impact of Sco on memory acquisition without affecting the locomotor activity, and also improved Sco-induced amnesia. It has been shown that administration of Sco at $0.056 \mathrm{mg} / \mathrm{kg}$ and more increases locomotor activity (as a noncognitive effect) in rats (Gholamreza et al. 2002; Chintoh et al. 2003). In our experiments, we used a Sco concentration of $1 \mathrm{mg} / \mathrm{kg}$ which is 18 -fold higher than the minimal effective dose; however, no change 
was observed in the locomotor activities in different experimental groups. Therefore, OOEO (and also Gal) treatment is likely to suppress the non-cognitive effects of Sco. Memory impairment caused by Sco administered intraperitoneally to rats at a dose of $1 \mathrm{mg} / \mathrm{kg}$ was assessed based on the NOR test, which provides a rapid performance assessment for rodents (Van Momtazi-Borojeni et al. 2017). Rats treated with Sco were unable distinguish between the novel and familiar objects, which ultimately showed us that recognition was significantly deficient in this group of animals. Upon OOEO treatment, however, Scoinduced deterioration of cognitive abilities in rats was found to be abolished, and improvements in memory performance were noted. The results of the MWM test demonstrated that the administration of Sco significantly reduced the discrimination index, escape rate and time spent in the target quadrant and increased latency to find the platform, all of which are indicators of learning skills and memory in rodents. OOEO administration, however, was found to ameliorate Sco-induced impairments on the discrimination index, latency to find the platform, escape rate and time spent in the target quadrant. Collectively, these results suggest that OOEO may prevent Sco-induced learning and memory impairments in rats.

Due to the important role of the cholinergic system in learning and memory, maintaining acetylcholine levels are critical for brain functions (Blake et al. 2014). The action of AChE breaks down the naturally occurring neurotransmitter acetylcholine into acetate and choline at synaptic sites, which terminates or suspends cholinergic transmission (Ballard et al. 2005). Accordingly, an agent promoting the activity of AChE should ideally impair memory via lowering acetylcholine levels as Sco achieved in the amnestic group. On the other hand, in the present study, the standard drug Gal and OOEO significantly reduced the activity of AChE and allowed the rats to retain the memory of the tasks they learned as observed in our rich array of behavioral experiments. This AChE inhibition could be attributed to one or more components of OOEO. Indeed, AChE from electric eel has previously been shown to be inhibited by carvacrol $\left(I C_{50}\right.$ : $0.063 \mathrm{mg} / \mathrm{ml}$ ) and its derivative thymohydroquinone $\left(I_{50}: 0.04 \mathrm{mg} / \mathrm{ml}\right)$ in an in-vitro setting (Jukic et al. 2007). Considering that impairments in the human brain cholinergic pathways are among the underlying causes of $A D$ and that the use of $A C h E$ inhibitors that increase acetylcholine levels in the CNS constitutes the essential remedy for the disease (Terry and Buccafusco 2003), the inhibition of AChE in vivo by OOEO suggests that this essential oil may represent a novel candidate therapeutic agent for $A D$.

The CNS is particularly susceptible to pro-oxidants because of its unique architecture and operation, exemplified by a high oxygen consumption concomitant with a high unsaturated lipid content and low antioxidant protection (Kowalczyk et al. 2020). Therefore, it is no surprise that the overproduction of reactive oxygen species (ROS) in the CNS is associated with several neurodegenerative diseases including AD. The most commonly affected brain regions are believed to be the hippocampus, substantia nigra, and striatum (Phaniendra et al. 2015). Our study confirms that oxidative stress is involved in Scoinduced dementia in rats as revealed by an increase in the concentration of MDA, a secondary oxidation product of polyunsaturated fatty acids, and a decrease in the concentration of $\mathrm{GSH}$, a major cellular antioxidant buffer molecule, in both hippocampus and frontal cortex. In contrary, the standard drug Gal and OOEO were able to significantly improve this oxidative stress profile in the single brain structures. 
ROS can also induce neuronal death in multiple forms including apoptosis (Fricker et al. 2018). Animal studies have shown that the activation and execution of apoptosis in neurons in the cortex and hippocampus impairs learning and memory (Kuhn et al. 2005; Sun et al. 2009). While encounter with Sco increased the bax/bcl-2 ratio and caspase levels in the frontal cortex and hippocampus of amnestic rats, Gal and OOEO treatments were effective in decreasing the production of apoptotic protein factors in both regions. Taken together, it is plausible to assume that the antioxidant and pro-survival properties of OOEO at a cellular scale may contribute to the reversal of Sco-induced memory deficits in rats.

Neuroinflammation can be defined as an inflammatory response within the CNS, which is usually caused by one of a variety of pathological insults including trauma, ischemia, infection, and toxins. The production of pro-inflammatory molecules (e.g., cytokines, chemokines, NO, and ROS) by innate immune cells, such as microglia/macrophages and astrocytes, in the course of neuroinflammation may ultimately result in synaptic dysfunction, impaired neurogenesis, and neuronal death (Leng and Edison, 2021). A major contribution to neuronal death is ROS generation by the induction or activation of inflammationrelated enzyme systems including COX-2, iNOS, and MPO. For instance, MPO has been shown to be aberrantly expressed in astrocytes in human AD brain (Maki et al. 2009). The involvement of MPO in disease pathogenesis is further supported by the presence of 3-chlorotyrosine, a specific biomarker of MPO-catalyzed oxidation, in the hippocampus from patients with AD (Green et al. 2009). In addition, activated macrophages/microglia are known to induce the expression of other downstream proinflammatory enzymes such as COX-2 and iNOS (Choi et al. 2009). It has been demonstrated that COX-2 levels are elevated in AD brain (Pasinetti and Aisen 1998; Yasojima et al. 1999; Earley et al. 2000) and that they correlate with the clinical progression of the disease (Ho et al. 2001). Similarly, iNOS expression has been found in the hippocampal region of the brain affected by $A D$ and linked to neuronal degeneration in the disease (Sunhee et al. 1999). Our computational predictions illustrate that carvacrol can be housed in the inhibitor-binding pockets of MPO, COX-2 and iNOS. In fact, COX-2 from sheep has previously been shown to be inhibited by carvacrol in an in-vitro setting (Landa et al. 2009). Furthermore, the potency of COX-2 inhibition by carvacrol $\left(I C_{50}: 0.8 \mu \mathrm{M}\right)$ has been found to be comparable to that by an NSAID. It is therefore plausible to assume that the in vivo observed anti-inflammatory action of oregano (Taleb et al. 2018) and other traditionally used carvacrol-rich plant drugs (Sosa et al. 2005) could be partly due to the modulation of pro-inflammatory enzyme activities.

\section{Statements \& Declarations}

\section{Declarations}

Acknowledgements: No support was received for this study.

Funding: "The authors declare that no funds, grants, or other support were received during the preparation of this manuscript."

Financial interests: The authors have no relevant financial or non-financial interests to disclose. 
Author contributions: Asli Aykac, Kerem Teralı, Dilek Özbeyli, Kemal Hüsnü Can Başer and Göksel Şener conceived the study design. Asli Aykac, Dilek Özbeyli, Seren Ede, Ömercan Albayrakand Göksel Şener were responsible for animal experiments. Asli Aykac and Kerem Teralı were responsible for molecular experiments and statistical analysis. Asli Aykac, Kerem Teralı and Dilek Özbeyli wrote the original draft manuscript. Asli Aykac, Kerem Teralı, Kemal Hüsnü Can Başer and Goksel Şener reviewed and edited final version of the manuscript. Asli Aykac, Kerem Teralı, Dilek Ozbeyli, Seren Ede, Ömercan Albayrak, Kemal Hüsnü Can Başer and Goksel Sener have seen and read the final version of the article. The corresponding author attests that all listed authors meet authorship criteria and that no others meeting the criteria have been omitted.

Availability of data: All data generated or analyzed during this study are included in this published article.

Conflicts of interest: The authors declare that they have no conflicts of interest.

Ethics approval: All procedures were carried out in accordance with the National Institute of Health Guide for the Care and Use of Laboratory Animals and the protocols were approved by the Marmara University Animal Care and Use Committee (MUHDEK approval no: 112.2016.mar)

\section{References}

1. Amiresmaeili A, Roohollahi S, Mostafavi A, Askari N (2018) Effects of oregano essential oil on brain TLR4 and TLR2 gene expression and depressive-like behavior in a rat model. Res Pharm Sci 13(2):130-141. http://doi.org/10.4103/1735-5362.223795

2. Antonova E, Parslow D, Brammer M, Simmons A, Williams S, Dawson GR, Morris R (2011) Scopolamine disrupts hippocampal activity during allocentric spatial memory in humans: an fMRI study using a virtual reality analogue of the Morris Water Maze. J Psychopharmacol 25(9):12561265. http://doi.org/10.1177/0269881110379285

3. Antunes M, Biala G (2012) The novel object recognition memory: neurobiology, test procedure, and its modifications. Cogn Process 13(2):93-110. http://doi.org/10.1007/s10339-011-0430-z

4. Aubele T, Kaufman R, Montalmant F, Kritzer MF (2008) Effects of gonadectomy and hormone replacement on a spontaneous novel object recognition task in adult male rats. Horm Behav 54(2):244-252. http://doi.org/10.1016/j.yhbeh.2008.04.001

5. Aykac A, Becer E, Özbeyli D, Şener G, Başer KHC (2020) Protective Effects of Origanum onites Essential Oil in the Methotrexate-Induced Rat Model: Role on Apoptosis and Hepatoxicity. Rec Nat Prod 14:(6):395-404. http://doi.org/10.25135/rnp.186.20.04.1631

6. Aykac A, Ozbeyli D, Uncu M, Ertaş B, Kılınc O, Şen A, Orun O, Sener G (2019) Evaluation of the protective effect of Myrtus communis in scopolamine-induced Alzheimer model through cholinergic receptors. Gene 689:194-201. http://doi.org/10.1016/j.gene.2018.12.007

7. Azizi Z, Ebrahimi S, Saadatfar E, Kamalinejad M, Majlessi N (2012) Cognitive-enhancing activity of thymol and carvacrol in two rat models of dementia. Behav Pharmacol 23(3):241-249. 
http://doi.org/10.1097/FBP.0b013e3283534301

8. Ballard CG, Greig NH, Guillozet-Bongaarts AL, Enz A, Darvesh S (2005) Cholinesterases: Roles in the Brain During Health and Disease. Curr Alzheimer Res 2(3):307-318. https://doi.org/10.2174/1567205054367838

9. Baser KH (2008) Biological and pharmacological activities of carvacrol and carvacrol bearing essential oils. Curr Pharm Des 14:3106-3119. http://doi.org/10.2174/138161208786404227

10. Capatina L, Boiangiu RS, Dumitru G, Napoli EM, Ruberto G, Hritcu L, Todirascu-Ciornea E (2020) Rosmarinus officinalis Essential Oil Improves Scopolamine-Induced Neurobehavioral Changes via Restoration of Cholinergic Function and Brain Antioxidant Status in Zebrafish (Danio rerio). Antioxidants (Basel) 9(1):62. http://doi.org/10.3390/antiox9010062

11. Chintoh A, Fulton J, Koziel N, Aziz M, Sud M, Yeomans JS (2003) Role of cholinergic receptors in locomotion induced by scopolamine and oxotremorine-M. Pharmacol Biochem Behav 76(1):53-61. http://doi.org/10.1016/s0091-3057(03)00196-5

12. Choi SH, Aid S, Bosetti F (2009) The distinct roles of cyclooxygenase-1 and -2 in neuroinflammation: implications for translational research. Trends Pharmacol Sci 30(4):174-181. http://doi.org/10.1016/j.tips.2009.01.002

13. Demirci F, Paper DH, Franz G, Başer KH (2004) Investigation of the Origanum onites L. essential oil using the chorioallantoic membrane (CAM) assay. J Agric Food Chem 52(2):251-254. http://doi.org/10.1021/jf034850k

14. Deng G, Wu C, Rong X, Li S, Ju Z, Wang Y, Ma C, Ding W, Guan H, Cheng X, Liu W, Wang C (2019) Ameliorative effect of deoxyvasicine on scopolamine-induced cognitive dysfunction by restoration of cholinergic function in mice. Phytomedicine 63:153007. http://doi.org/10.1016/j. phymed.2019.153007

15. Fährrolfes R, Bietz S, Flachsenberg F, Meyder A, Nittinger E, Otto T, Volkamer A, Rarey M (2017) ProteinsPlus: a web portal for structure analysis of macromolecules. Nucleic Acids Res 45(W1):W337-W343. http://doi.org/10.1093/nar/gkx333

16. Farlow MR, Miller ML, Pejovic V (2008) Treatment options in Alzheimer's disease: maximizing benefit, managing expectations. Dement Geriatr Cogn Disord 25(5):408-422. http://doi.org/10.1159/000122962

17. Ferreira-Vieira TH, Guimaraes IM, Silva FR, Ribeiro FM (2016) Alzheimer's disease: Targeting the Cholinergic System. Curr Neuropharmacol 14(1):101-115. http://doi.org/10.2174/1570159x13666150716165726

18. Flachsenberg F, Meyder A, Sommer K, Penner P, Rarey MA (2020) Consistent Scheme for GradientBased Optimization of Protein-Ligand Poses. J Chem Inf Model 60(12):6502-6522. http://doi.org/10.1021/acs.jcim.0c01095

19. Fricker M, Tolkovsky AM, Borutaite V, Coleman M, Brown GC (2018) Neuronal Cell Death. Physiol Rev 98(2):813-880. http://doi.org/10.1152/physrev.00011.2017 
20. Garcin ED, Arvai AS, Rosenfeld RJ, Kroeger MD, Crane BR, Andersson G, Andrews G, Hamley PJ, Mallinder PR, Nicholls DJ, St-Gallay SA, Tinker AC, Gensmantel NP, Mete A, Cheshire DR, Connolly S, Stuehr DJ, Aberg A, Wallace AV, Tainer JA, Getzoff ED (2008) Anchored plasticity opens doors for selective inhibitor design in nitric oxide synthase. Nat Chem Biol 4(11):700-707. http://doi.org/10.1038/nchembio.115

21. Geerts H, Guillaumat PO, Grantham C, Bode W, Anciaux K, Sachak S (2005) Brain levels and acetylcholinesterase inhibition with galantamine and donepezil in rats, mice, and rabbits. Brain Res 1033(2):186-193. http://doi.org/10.1016/j.brainres.2004.11.042

22. Ghasemi S, Moradzadeh M, Hosseini M, Beheshti F, Sadeghnia HR (2019) Beneficial effects of Urtica dioica on scopolamine-induced memory impairment in rats: protection against acetylcholinesterase activity and neuronal oxidative damage. Drug Chem Toxicol 42(2):167-175.

http://doi.org/10.1080/01480545.2018.1463238

23. Gholamrezal P, Pratt JA, Nima D (2002) Effects of low-dose scopolamine on locomotor activity: No dissociation between cognitive and non-effects. Neurosci Res Commun 31(3):165-174. https://doi.org/10.1002/nrc.10049

24. Green PS, Mendez AJ, Jacob JS, Crowley JR, Growdon W, Hyman BT, Heinecke JW (2004) Neuronal expression of myeloperoxidase is increased in Alzheimer's disease. J Neurochem 90(3):724-733. http://doi.org/10.1111/j.1471-4159.2004.02527.x

25. Gürbüz P, Martinez A, Pérez C, Martínez-González L, Göger F, Ayran I (2019) Potential anti-Alzheimer effects of selected Lamiaceae plants through polypharmacology on glycogen synthase kinase- $3 \beta, \beta-$ secretase, and casein kinase 1ס. Ind Crop Prod 138:111431.

https://doi.org/10.1016/j.indcrop.2019.05.080

26. Henzler AM, Urbaczek S, Hilbig M, Rarey M (2014) An integrated approach to knowledge-driven structure-based virtual screening. J Comput Aided Mol Des 28(9):927-939. http://doi.org/10.1007/s10822-014-9769-4

27. Ho L, Purohit D, Haroutunian V, Luterman JD, Willis F, Naslund J, Buxbaum JD, Mohs RC, Aisen PS, Pasinetti GM (2001) Neuronal cyclooxygenase 2 expression in the hippocampal formation as a function of the clinical progression of Alzheimer disease. Arch Neurol 58(3):487-492. http://doi.org/10.1001/archneur.58.3.487

28. Howes M-JR, Perry NSL, Houghton PJ (2003) Plants with traditional uses and activities relevant to the management of Alzheimer's disease and other cognitive disorders. Phytother Res 17(1):1-18. http://doi.org/10.1002/ptr.1280

29. Jordan F, Quinn TJ, McGuinness B, Passmore P, Kelly JP, Tudur Smith C, Murphy K, Devane D (2020) Aspirin and other non-steroidal anti-inflammatory drugs for the prevention of dementia. Cochrane Database Syst Rev 4(4):CD011459. http://doi.org/10.1002/14651858.CD011459.pub2

30. Jukic M, Politeo O, Maksimovic M, Milos M, Milos M (2007) In vitro acetylcholinesterase inhibitory properties of thymol, carvacrol and their derivatives thymoquinone and thymohydroquinone. Phytother Res 21(3):259-261. http://doi.org/10.1002/ptr.2063 
31. Kim S, Chen J, Cheng T, Gindulyte A, He J, He S, Li Q, Shoemaker BA, Thiessen PA, Yu B, Zaslavsky L, Zhang J, Bolton EE (2019) PubChem 2019 update: improved access to chemical data. Nucleic Acids Res 8(D1):47. D1102-D1109. http://doi.org/10.1093/nar/gky1033

32. Kinney JW, Bemiller SM, Murtishaw AS, Leisgang AM, Salazar AM, Lamb BT (2018) Inflammation as a central mechanism in Alzheimer's disease. Alzheimers Dement (NY) 4:575-590. http://doi.org/10.1016/j.trci.2018.06.014

33. Kowalczyk J, Kurach Ł, Boguszewska-Czubara A, Skalicka-Woźniak K, Kruk-Słomka M, Kurzepa J, Wydrzynska-Kuźma M, Biała G, Skiba A, Budzyńska B (2020) Bergapten Improves ScopolamineInduced Memory Impairment in Mice via Cholinergic and Antioxidative Mechanisms. Front Neurosci 14:730. http://doi.org/10.3389/fnins.2020.00730

34. Kuhn HG, Biebl M, Wilhelm D, Li M, Friedlander RM, Winkler J (2005) Increased generation of granule cells in adult Bcl-2-overexpressing mice: a role for cell death during continued hippocampal neurogenesis. Eur J Neurosci 22(8):1907-1915. http://doi.org/10.1111/j.1460-9568.2005.04377.x

35. Landa P, Kokoska L, Pribylova M, Vanek T, Marsik P (2009) In vitro anti-inflammatory activity of carvacrol: Inhibitory effect on COX-2 catalyzed prostaglandin $\mathrm{E}_{2}$ biosynthesisb. Arch Pharm Res 32:75-78. https://doi.org/10.1007/s12272-009-1120-6

36. Leng F, Edison P (2021) Neuroinflammation and microglial activation in Alzheimer disease: where do we go from here? Nat Rev Neurol 17:157-172. https://doi.org/10.1038/s41582-020-00435-y

37. Lowry OH, Rosebrough NJ, Farr AL, Randall RJ (1951) Protein measurement with the Folin phenol reagent. J Biol Chem 193(1):265-275

38. Maki RA, Tyurin VA, Lyon RC, Hamilton RL, DeKosky ST, Kagan VE, Reynolds WF (2009) Aberrant expression of myeloperoxidase in astrocytes promotes phospholipid oxidation and memory deficits in a mouse model of Alzheimer disease. J Biol Chem 284(5):3158-3169.

http://doi.org/10.1074/jbc.M807731200

39. Momtazi-Borojeni AA, Sadeghi-Aliabadi H, Rabbani M, Ghannadi A, Abdollahi E (2017) Cognitive enhancing of pineapple extract and juice in scopolamine-induced amnesia in mice. Res Pharm Sci 12(3):257-264. doi:10.4103/1735-5362.207198

40. Orhan I, Kartal M, Kan Y, Sener B (2008) Activity of essential oils and individual components against acetyl- and butyrylcholinesterase. Z Naturforsch C J Biosci 63(7-8):547-553.

https://doi.org/10.1515/znc-2008-7-813

41. Orlando BJ, Malkowski MG (2016) Crystal structure of rofecoxib bound to human cyclooxygenase-2. Acta Crystallogr F Struct Biol Commun 72:772-776. http://doi.org/10.1107/S2053230X16014230

42. Pasinetti GM, Aisen PS (1998) Cyclooxygenase-2 expression is increased in frontal cortex of Alzheimer's disease brain. Neuroscience 87(2):319-324. http://doi.org/10.1016/s03064522(98)00218-8

43. Paxinos G, Watson C (2007) The rat brain in stereotaxic coordinates, 6th edn. Academic Press, San Diego, CA, USA 
44. Perry NS, Bollen C, Perry EK, Ballard C (2003) Salvia for dementia therapy: review of pharmacological activity and pilot tolerability clinical trial. Pharmacol Biochem Behav 75(3):651-659. http://doi.org/10.1016/s0091-3057(03)00108-4

45. Phaniendra A, Jestadi DB, Periyasamy $L$ (2015) Free radicals: properties, sources, targets, and their implication in various diseases. Indian J Clin Biochem 30(1):11-26. http://doi.org/10.1007/s12291014-0446-0

46. Rabiei Z, Mokhtari S, Asgharzade S, Gholami M, Rahnama S, Rafieian-Kopaei M (2015) Inhibitory effect of Thymus vulgaris extract on memory impairment induced by scopolamine in rat. Asian Pac J Trop Biomed 5(10):845-851. https://doi.org/10.1016/j.apjtb.2015.07.006

47. Rahnama S, Rabiei Z, Alibabaei Z, Mokhtari S, Rafieian-Kopaei M, Deris F (2015) Anti-amnesic activity of Citrus aurantium flowers extract against scopolamine-induced memory impairments in rats. Neurol Sci 36(4):553-560. http://doi.org/10.1007/s10072-014-1991-2

48. Rezvani AH, Cauley M, Sexton H, Xiao Y, Brown ML, Paige MA, McDowell BE, Kellar KJ, Levin ED (2011) Sazetidine-A, a selective a4 $\beta 2$ nicotinic acetylcholine receptor ligand: effects on dizocilpine and scopolamine-induced attentional impairments in female Sprague-Dawley rats.

Psychopharmacology 215(4):621-630. http://doi.org/10.1007/s00213-010-2161-8

49. Rogóż Z, Kabziński M, Sadaj W, Rachwalska P, Gądek-Michalska A (2012) Effect of cotreatment with fluoxetine or mirtazapine and risperidone on the active behaviors and plasma corticosterone concentration in rats subjected to the forced swim test. Pharmacol Rep 64:1391-1399. http://doi.org/10.1016/s1734-1140(12)70936-2

50. Savelev SU, Okello EJ, Perry EK (2004) Butyryl- and acetyl-cholinesterase inhibitory activities in essential oils of Salvia species and their constituents. Phytother Res 18:315-324. https://doi.org/10.1002/ptr.1451

51. Schellhammer I, Rarey M (2007) TrixX: structure-based molecule indexing for large-scale virtual screening in sublinear time. J Comput Aided Mol Des 21(5):223-238. http://doi.org/10.1007/s10822-007-9103-5

52. Schöning-Stierand K, Diedrich K, Fährrolfes R, Flachsenberg F, Meyder A, Nittinger E, Steinegger R, Rarey M (2020) ProteinsPlus: interactive analysis of protein-ligand binding interfaces. Nucleic Acids Res 48(W1):W48-W53. http://doi.org/10.1093/nar/gkaa235

53. Soria Lopez JA, González HM, Léger GC (2019) Alzheimer's disease. Handb Clin Neurol 167:231255. http://doi.org/10.1016/B978-0-12-804766-8.00013-3

54. Sosa S, Altinier G, Politi M, Braca A, Morelli I, Della Loggia R (2005) Extracts and constituents of Lavandula multifida with topical anti-inflammatory activity. Phytomedicine 12(4):271-277. http://doi.org/10.1016/j.phymed.2004.02.007

55. Sun XQ, Xu ZP, Zhang S, Cao XS, Liu TS (2009) Simulated weightlessness aggravates hypergravityinduced impairment of learning and memory and neuronal apoptosis in rats. Behav Brain Res 199(2):197-202. http://doi.org/10.1016/j.bbr.2008.11.035 
56. Sunhee CL, Zhao ML, Hirano A, Dickson DW (1999) Inducible Nitric Oxide Synthase Immunoreactivity in the Alzheimer Disease Hippocampus: Association with Hirano Bodies, Neurofibrillary Tangles, and Senile Plaques. J Neuropathol Exp Neurol 58(11):1163-1169. https://doi.org/10.1097/00005072199911000-00006

57. Taleb MH, Abdeltawab NF, Shamma RN, Abdelgayed SS, Mohamed SS, Farag MA, Ramadan MA (2018) Origanum vulgare L. Essential Oil as a Potential Anti-Acne Topical Nanoemulsion-In Vitro and In Vivo Study. Molecules 23(9):2164. http://doi.org/10.3390/molecules23092164

58. Tang KS (2019) The cellular and molecular processes associated with scopolamine-induced memory deficit: A model of Alzheimer's biomarkers. Life Sci 233:116695.

http://doi.org/10.1016/j.lfs.2019.116695

59. Tepe B, Cakir A, Sihoglu Tepe A (2016) Medicinal Uses, Phytochemistry, and Pharmacology of Origanum onites (L.): A Review. Chem Biodivers 13(5):504-520. http://doi.org/10.1002/cbdv.201500069

60. Vorhees CV, Williams MT (2006) Morris water maze: procedures for assessing spatial and related forms of learning and memory. Nat Protoc 1(2):848-858. http://doi.org/10.1038/nprot.2006.116

61. Wang C, Cai Z, Wang W, Wei M, Kou D, Li T, Yang Z, Guo H, Le W, Li S (2019) Piperine attenuates cognitive impairment in an experimental mouse model of sporadic Alzheimer's disease. J Nutr Biochem 70:147-155. http://doi.org/10.1016/j.jnutbio.2019.05.009

62. Wurtz NR, Viet A, Shaw SA, Dilger A, Valente MN, Khan JA, Jusuf S, Narayanan R, Fernando G, Lo F, Liu X, Locke GA, Kopcho L, Abell LM, Sleph P, Basso M, Zhao L, Wexler RR, Duclos F, Kick EK (2018) Potent Triazolopyridine Myeloperoxidase Inhibitors. ACS Med Chem Lett 9(12):1175-1180. http://doi.org/10.1021/acsmedchemlett.8b00308

63. Xu P, Wang K, Lu C, Dong L, Gao L, Yan M, Aibai S, Yang Y, Liu X (2017) The Protective Effect of Lavender Essential Oil and Its Main Component Linalool against the Cognitive Deficits Induced by DGalactose and Aluminum Trichloride in Mice. Evid Based Complement Alternat Med 2017:7426538. http://doi.org/10.1155/2017/7426538

64. Yasojima K, Schwab C, McGeer EG, McGeer PL (1999) Distribution of cyclooxygenase-1 and cyclooxygenase-2 mRNAs and proteins in human brain and peripheral organs. Brain Res 830(2):226-236. http://doi.org/10.1016/s0006-8993(99)01389-x

65. Zhou J, Yang WS, Suo DQ, Li Y, Peng L, Xu LX, Zeng KY, Ren T, Wang Y, Zhou Y, Zhao Y, Yang LC, Jin X (2018) Moringa oleifera Seed Extract Alleviates Scopolamine-Induced Learning and Memory Impairment in Mice. Front Pharmacol 9:389. http://doi.org/10.3389/fphar.2018.00389

66. Zhou J, Yang WS, Suo DQ, Li Y, Peng L, Xu LX, Zeng KY, Ren T, Wang Y, Zhou Y, Zhao Y, Yang LC, Jin X (2018) Moringa oleifera Seed Extract Alleviates Scopolamine-Induced Learning and Memory Impairment in Mice. Front Pharmacol 9:389. http://doi.org/10.3389/fphar.2018.00389

\section{Figures}




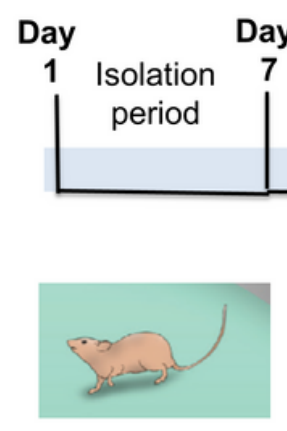

Scopolamine (1 $\mathrm{mg} / \mathrm{kg}$, i.p)

Scopolamine + Galantamine $(1.5 \mathrm{mg} / \mathrm{kg}$, i.p)

Origanum onites essential oil $(0.25 \mathrm{ml} / \mathrm{kg}, \mathrm{p} .0)$

Scopolamine + Origanum onites essential oil

Molecular docking

- MWM test
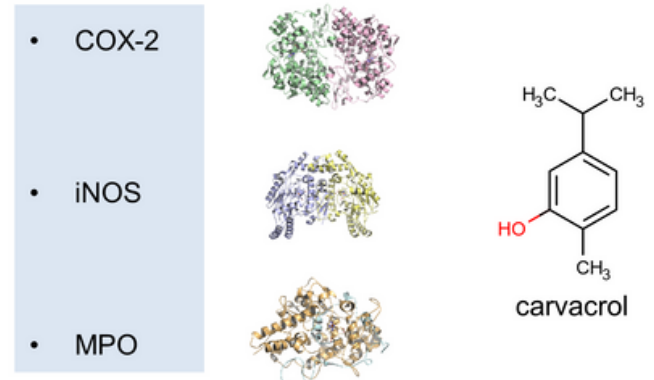

- LA test

NOR test

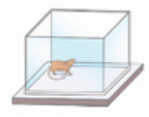

Day

29 experiments

Sacrifice

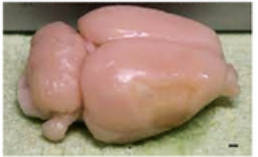

Hippocampus \& frontal cortex dissection

Biochemical analysis Western blotting

- AChE activity

- MDA levels

- GSH levels

- bax/bcl-2 ratio

- casp-3

- casp-9

\section{Figure 1}

Timeline of the experimental design.

AChE: acetylcholinesterase; bax: bcl-2 associated X protein; bcl-2: B-cell lymphoma 2; casp-3: caspase-3, casp-9: caspase-9; COX-2: cyclooxygenase-2; GSH: glutathione; iNOS: inducible nitric oxide synthase; LA: locomotor activity; MDA: malondialdehyde; MPO: myeloperoxidase; MWM: Morris water maze; NOR: novel object recognition 
$\square$ Control Sco $\square$ Gal $\square$ OOEO

a

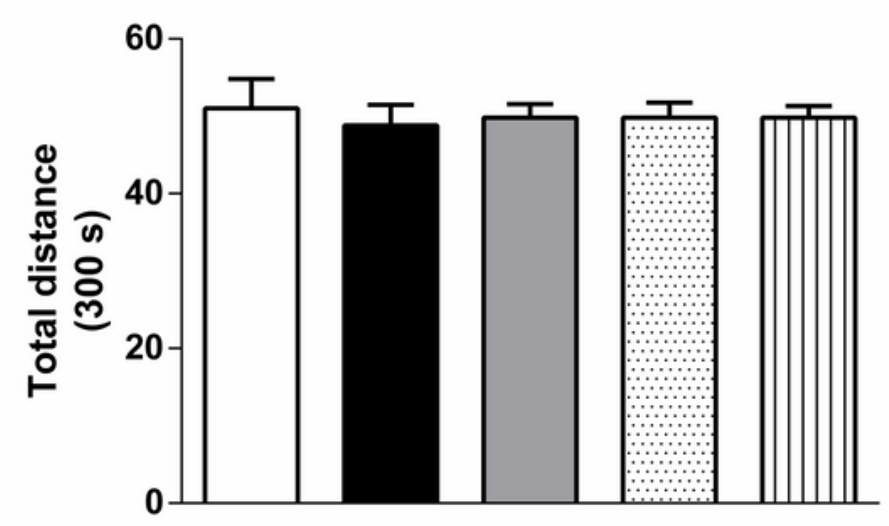

b

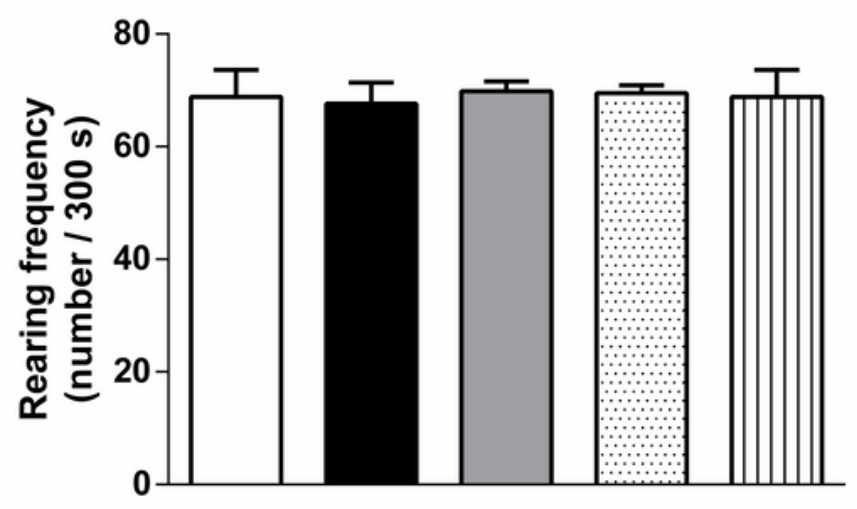

C

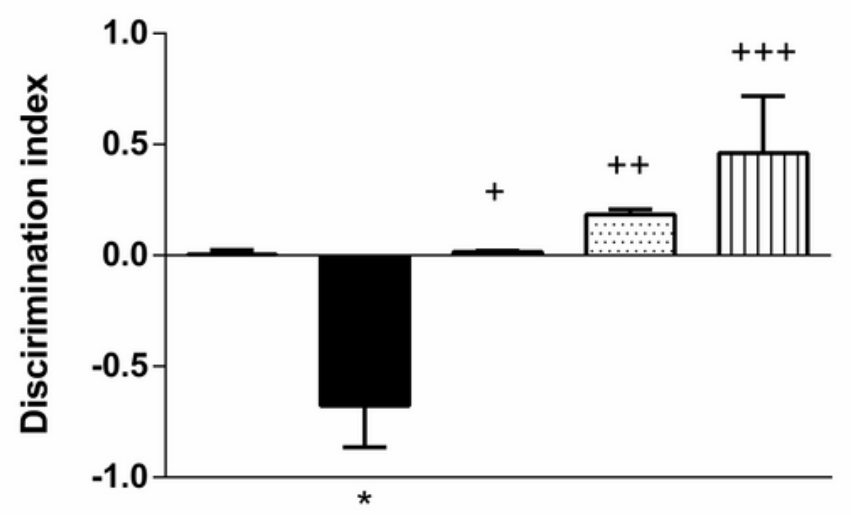

\section{Figure 2}

$\mathbf{a}$ Total distance ( $5 \mathrm{~min}$ ) and $\mathbf{b}$ rearing frequency (number/300 s) obtained from open field test, which was used to assess locomotor activity in an attempt to determine the effects of drug administration treatments on cognitive behavior. $\mathbf{c}$ Discrimination index (ranging from -1 to +1 ) obtained from new object recognition test, which was used to assess short-term recognition memory. 
Six rats per group. ${ }^{*} p<0.05$ vs. control and ${ }^{+} p<0.05$ vs. scopolamine-induced amnesia group.

- Control $-\mathrm{sco}-\mathrm{Gal}-$ DOEO $-\mathrm{scO+OOEO}$

a

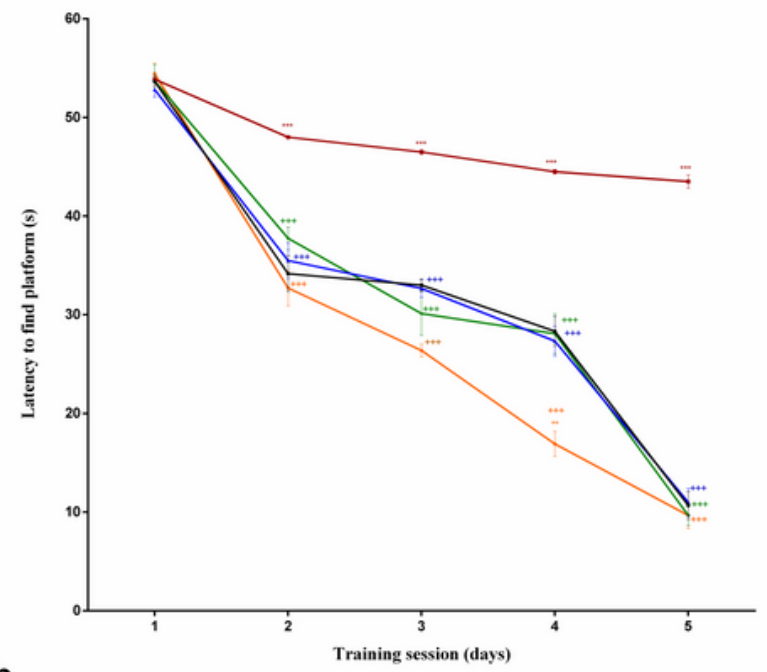

b

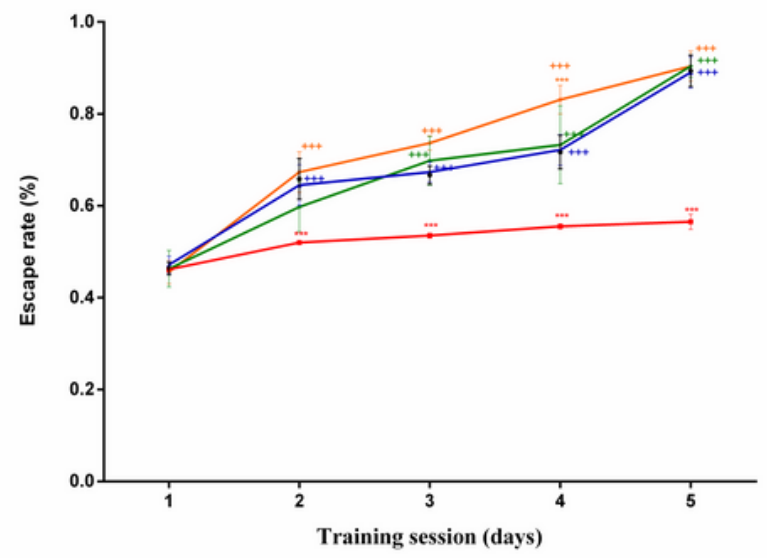

C
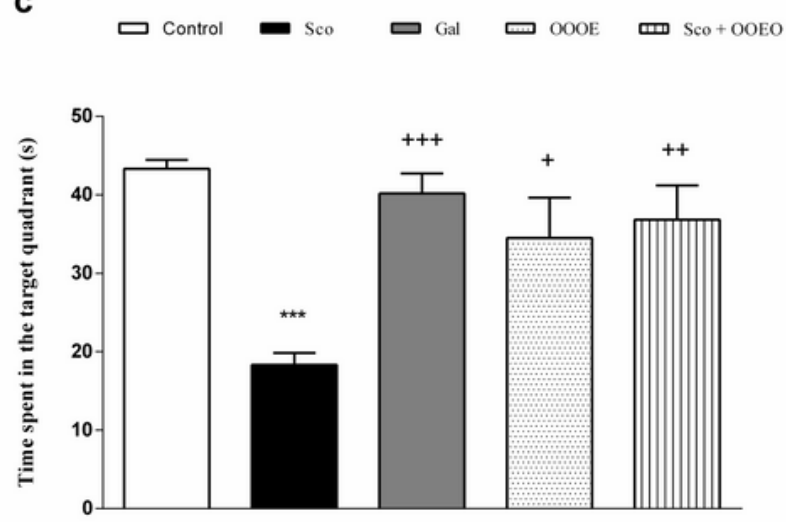

Figure 3

Effects of Origanum onites essential oil on scopolamine-induced impairment of cognition, learning and recognition and spatial memory function. a Latency to find platform (s), b escape rate (\%) and time spent in the target quadrant(s) in the Morris water maze. 
Six rats per group. ${ }^{*} p<0.05$ vs. control and ${ }^{+} p<0.05$ vs. scopolamine-induced amnesia group.

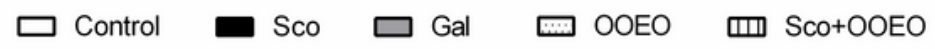

a

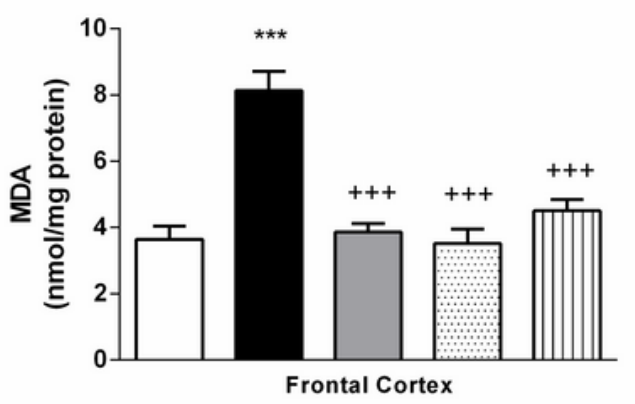

c

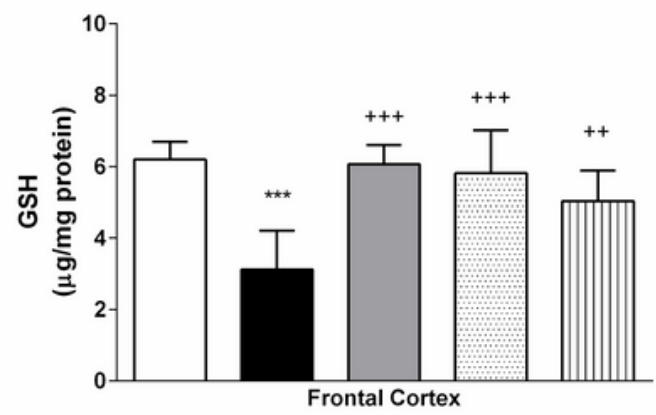

e

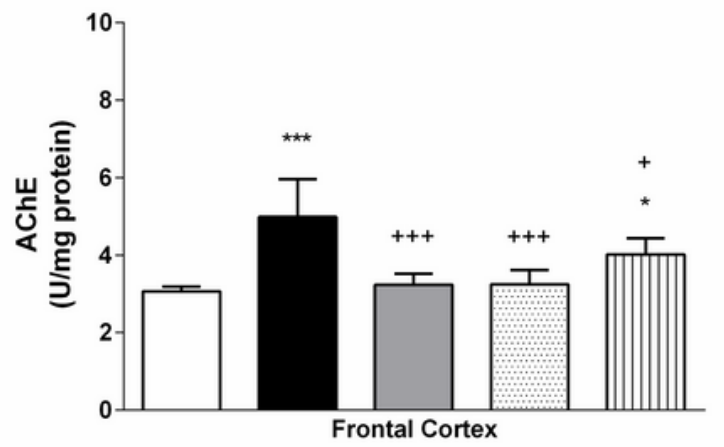

b

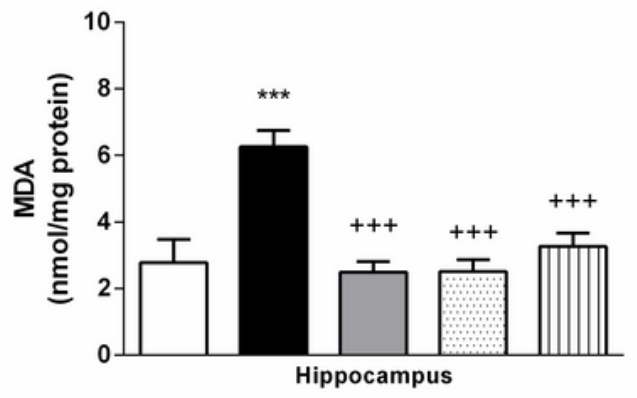

d

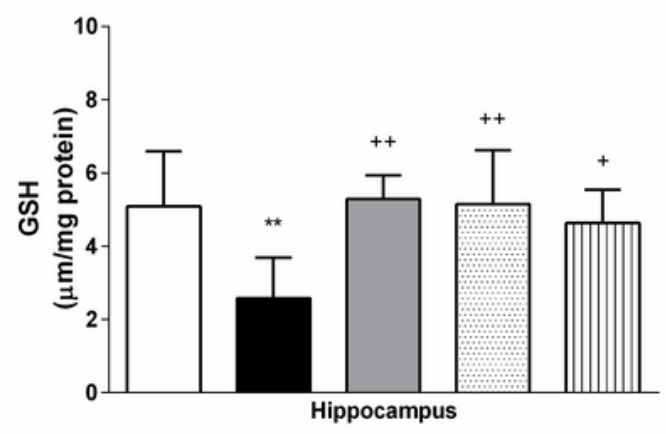

f

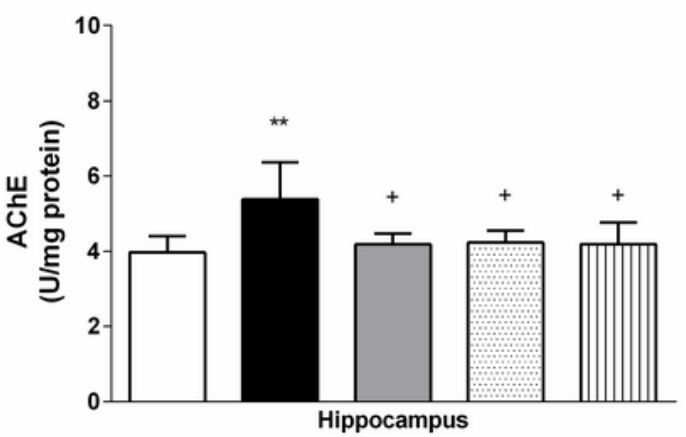

Figure 4 
a-b Acetylcholinesterase (AChE) activity, $\mathbf{c}-\mathbf{d}$ malondialdehyde (MDA) levels and $\mathbf{d}$-e reduced glutathione (GSH) levels in the frontal cortex and hippocampal regions of scopolamine-induced amnestic rats.

Six rats per group. ${ }^{\star} p<0.05$ vs. control and ${ }^{+} p<0.05$ vs. scopolamine-induced amnesia group.

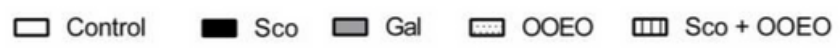

\section{Frontal cortex}

a

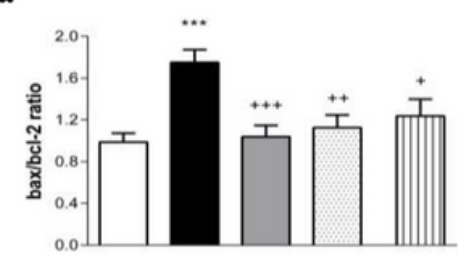

c

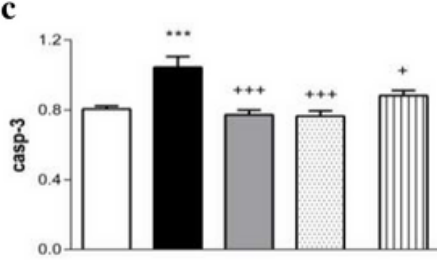

e

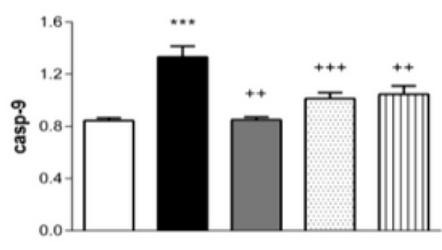

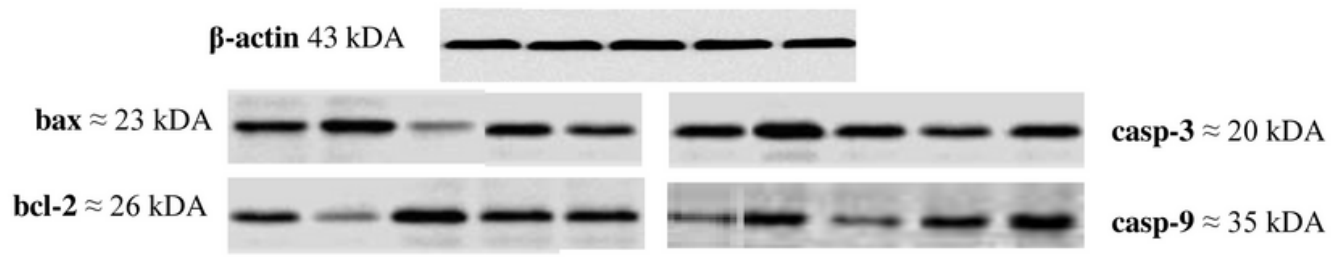

Hippocampus

b

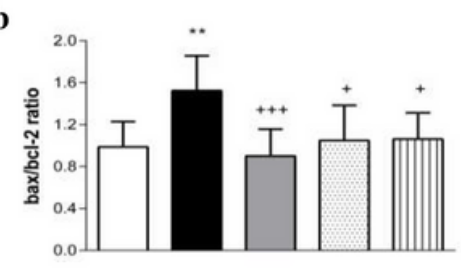

d

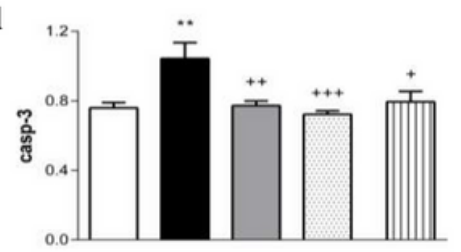

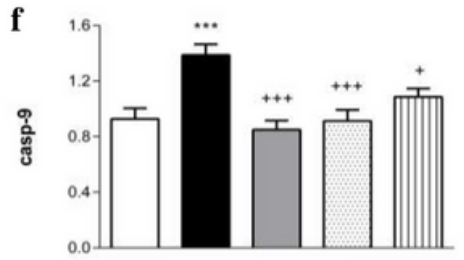

\section{Figure 5}

The density of immunoblotting of $\mathbf{a}-\mathbf{b}$ bax/bcl-2 ratio, $\mathbf{c}-\mathbf{d}$ casp-3 levels, and $\mathbf{e}-\mathbf{f}$ casp-9 levels of the hippocampal and frontal cortex regions of rats in scopolamine-induced $A D$ rat model $(n=6)$.

Six rats per group. ${ }^{*} p<0.05$ vs. control and ${ }^{+} p<0.05$ vs. scopolamine-induced amnesia group. Sco: scopolamine; Gal: galantamine; OOEO: Origanum onites essential oil; Sco+OOEO: scopolamine plus Origanum onites essential oil 
a

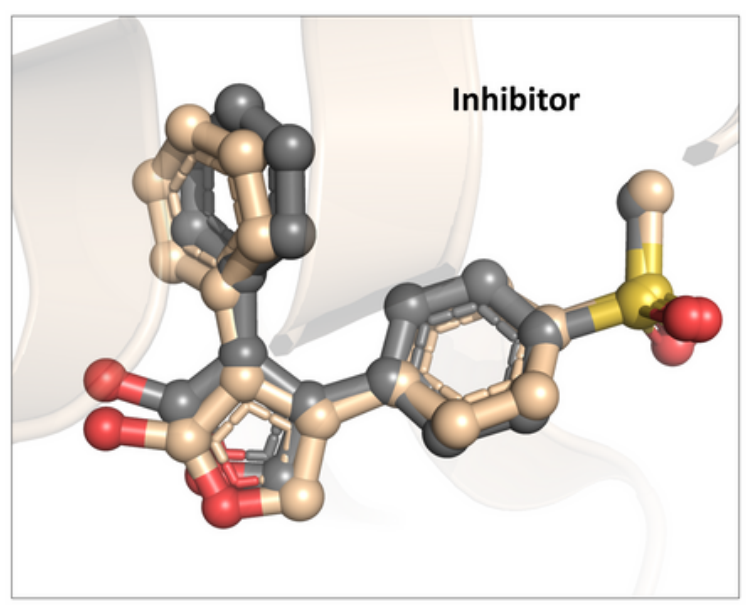

C

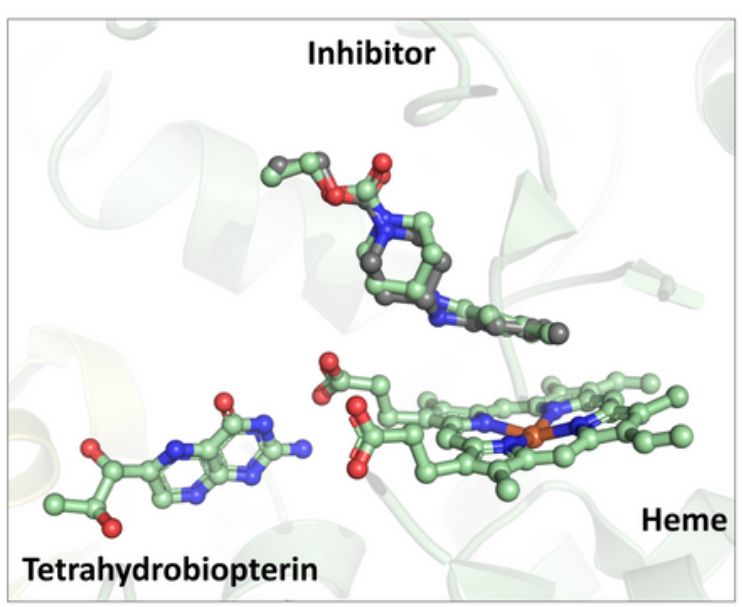

e

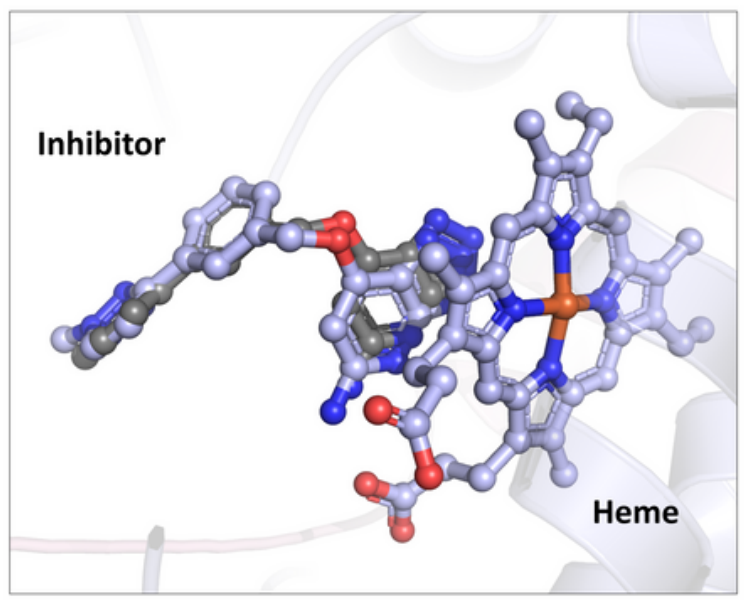

b

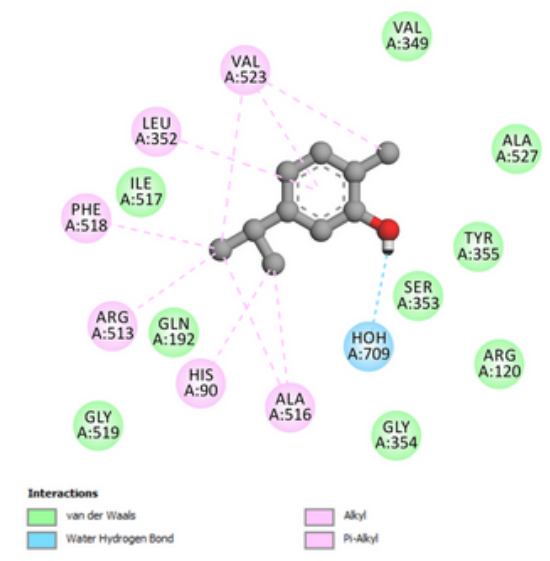

d
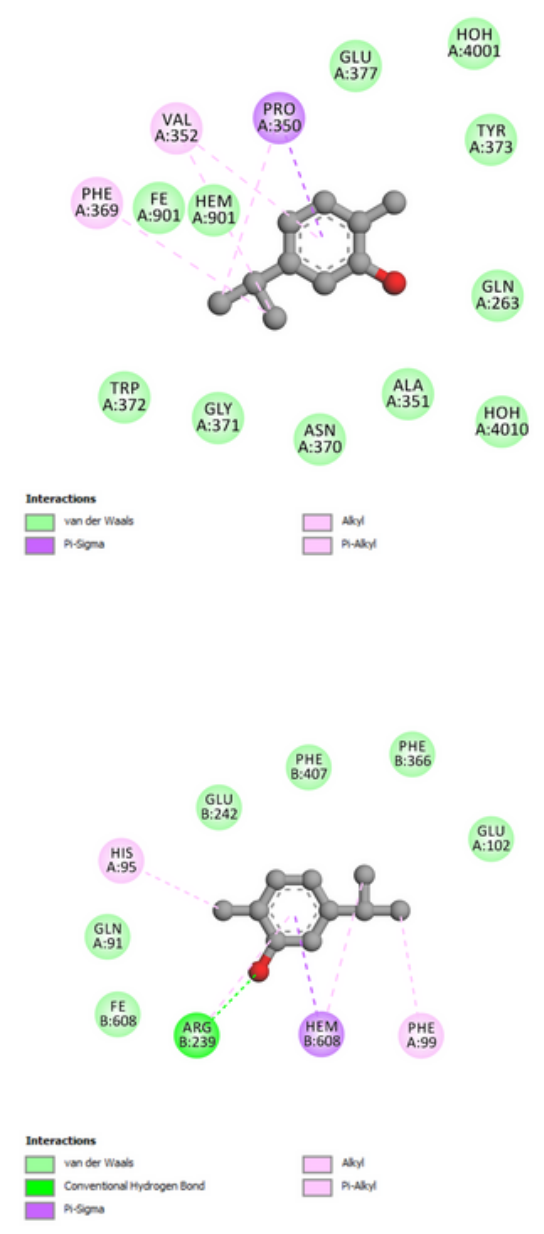

\section{Figure 6}

Redocking results showing the superposed structures of the docked and native ligands in the inhibitorbinding pockets of a cyclooxygenase-2 (COX-2), $\mathbf{b}$ inducible nitric oxide synthase (iNOS) and $\mathbf{c}$ myeloperoxidase (MPO). Cross-docking results showing the energetically favorable non-covalent interactions that anchor the predicted binding modes of carvacrol to the inhibitor-binding pockets of $\mathbf{d}$ COX-2, e iNOS and $\mathbf{f}$ MPO. The images a-c were rendered using the PyMOL Molecular Graphics System, 
v1.8 (Schrödinger LLC, Portland, OR, USA). The images $\mathbf{d}-\mathbf{f}$ were rendered using Discovery Studio Visualizer, v16.1.0 (Dassault Systèmes BIOVIA Corp., San Diego, CA, USA). 